\title{
Luteal Fazda Vajinal Laktobasil Desteğinin IVF/ICSI Sikluslarında Taze Embriyo Transferi Uygulanan Hastalarda İmplantasyon Oranlarına Etkisi
}

\author{
Kiper ASLAN ${ }^{1}$, Işıl KASAPOĞLU ${ }^{1}$, Göktan KUŞPINAR ${ }^{2}$, Berrin AVCI $^{2}$, \\ Gürkan UNCU ${ }^{1}$ \\ 1 Bursa Uludağ Üniversitesi Tıp Fakültesi, Kadın Hastalıkları ve Doğum Anabilim Dalı, Bursa. \\ 2 Bursa Uludağ Üniversitesi Tıp Fakültesi, Histoloji ve Embriyoloji Anabilim Dalı, Bursa.
}

\section{ÖZET}

Bu prospektif çalışmanın amacı IVF/ICSI sikluslarında taze embriyo transferi uygulanan infertil hastalarda luteal fazda vajinal laktobasil desteğinin implantasyon oranlarına etkisini araştırmaktır. Vajinal mikrobiyota ve infertilite ilişkisi günümüzde oldukça popüler bir araştırma konusudur ve yapılan çalışmalarda bozulmuş vajinal mikrobiyotanın infertil hastalarda gebelik sonuçlarını olumsuz olarak etkilediği bilinmektedir. Biz de bu sebeple çalıșmamızda 88 infertil hastaya kontrollü ovaryan hiperstimülasyon sonrası oosit toplandığı gün vajinal $1 \mathrm{x} 4$ tablet vajinal laktobasil desteği sağlayarak, gebelik sonuçlarını laktobasil desteği uygulanmayan 88 kontrol hastası ile karşılaştırdık. Sonuçlarda grupların demografik verileri birbirine benzerdi. Ve çalıșmanın birincil sonucu olan implantasyon oranları çalıșma grubunda \%38,6 kontrol grubunda \%32,9 olarak bulundu. Sonuçlar kontrol grubunda daha yüksek olmasına rağmen istatistiksel olarak benzerdi. Çalışmanın sonucu olarak taze embriyo transferi yapılan infertil hastalarda luteal fazda laktobasil desteği sağlanmasının gebelik sonuçlarına etkisi gözlenmedi.

Anahtar Kelimeler: İnfertilite. Mikrobiyota. Laktobasil. Luteal Faz Desteği.

Implantation Rates with Adding Vaginal Lactobacilli to Luteal Phase Support in Patients Undergoing Fresh Embryo Transfer in IVF/ICSI Cycles.

\begin{abstract}
This prospective study aims to clinically evaluate the effect of adding vaginal lactobacilli to luteal phase support implantation rates in patients undergoing fresh embryo transfer in IVF/ICSI cycles. The relationship between vaginal microbiota and infertility is a popular investigation field, and recent studies show that dysbiotic vaginal microbiota is related to poor pregnancy results in infertile patients. Thus, we enrolled 88 infertile patients who underwent ICSI procedure in the study group. We applied $1 \mathrm{x} 4$ tablets of lactobacillus through the vagina on the day of the oocyte pick up procedure. The pregnancy results were compared with the 88 patients who did not receive any lactobacillus support. The demographic parameters of the groups were comparable. Implantation rates were $38.6 \%$ in the study group and $32,9 \%$ percent in the control group. Although the implantation rate was higher in the study group, the difference was not statically significant. As a result, adding vaginal lactobacilli to luteal phase support does not improve implantation rates in patients undergoing fresh embryo transfer in IVF/ICSI cycles.
\end{abstract}

Key Words: Infertility. Microbiota. Lactobacillus. Luteal Phase Support.

Geliş Tarihi: 04.Mayıs.2020

Kabul Tarihi: 09.Temmuz.2020

Dr. Kiper ASLAN

Bursa Uludağ Üniversitesi Tıp Fakültesi,

Kadın Hastalıkları ve Doğum Anabilim Dalı,

Bursa.

Tel: 02242952541

E-posta: kiperaslan@yahoo.com.tr

\section{Yazarların ORCID ID Bilgisi:}

Kiper ASLAN: 0000-0002-9277-7735

Işıl KASAPOĞLU: 0000-0002-1953-2475

Göktan KUSPPINAR: 0000-0002-0338-8368

Berrin AVCl: 0000-0001-8135-5468

Gürkan UNCU: 0000-0001-7660-8344
İnsan Genom Projesi'nin 2001 yılında tüm dünyaya duyurulması, biyoloji alanında oldukça önemli gelişmelere öncülük etmiştir. ${ }^{1}$ Bu projenin devamında 2007 yılında İnsan Mikrobiyom Projesi açıklanmıştır. ${ }^{2}$ Mikrobiyom, insan vücudunda sağlık ve hastalık durumları ile ilişkili olduğu düşünülen, vücuttaki tüm mikroorganizmaların ekolojik ilişkilerinin oluşturmuş olduğu tablodur. İnsan mikrobiyom projesinde, mikrobiyomlar vücutta birçok alanda tanımlanmıştır ve vajinal mikrobiyota bunlar arasında çalışmalara en çok konu olanlardan biridir. Vajinal mikrobiyota yaş, cinsel aktivite, gebelik, hormon kullanımı gibi faktörlerden etkilenebilmektedir. ${ }^{3}$ Doğum şeklinin vajinal doğum ya da sezaryen olması durumunda doğan çocukta 
mikrobiyota farklılıklarının olduğu ve doğum şeklinin mikrobiyom gelişimi üzerinde önemli etkisi olduğu birçok çalışmada savunulmuştur. ${ }^{4,5}$

Vajinal mikrobiyotanın infertilite ve yardımcı üreme tekniklerindeki yeri henüz tam olarak anlaşılamamıştır. Ancak Mikoplazma, Klamidya ve Neisseria Gonore gibi mikroorganizmaların infertilite ile ilişkili olabileceği ve bakteriyel vajinozis gibi hastalıklara sebep olarak mikrobiyotada değişiklikler üzerinden infertiliteye yol açabileceği düşünülmektedir. ${ }^{6}$ Vajinal floranın büyük çoğunluğunu laktobasil türleri oluşturmaktadır ve laktobasiller gebeliğin oluşabilmesi için uygun ortamın sağlanmasında önemli rol oynamaktadırlar. ${ }^{7}$ Laktobasillerin bu uygun ortamı laktik asit üretimi ve hidrojen peroksit geri dönüşümünü sağlayarak yaptığı bilinmektedir. ${ }^{8}$ Tüp bebek tedavisi alan hastaların \%17.7'inin üreme organlarında anormal mikrobiyom olduğu gösterilmiştir ve günümüzde bu anormalliği gösterebilmek için vajinal mikrobiyom gen haritası üzerinde çalışmalar yapılmaktadır. ${ }^{9}$ Biz de çalışmamızda taze embriyo transferi yapılacak olan infertil hastalarda luteal faz sırasında vajinal laktobasil kullanımının embriyo implantasyonuna etkisini araştırmayı hedefledik.

\section{Gereç ve Yöntem}

$\mathrm{Bu}$ prospektif çalışma Bursa Uludağ Üniversitesi Kadın Hastalıkları ve Doğum Anabilim Dalı Tüp Bebek Merkezi'nde yapıldı. Çalışma için etik kurul onayı Bursa Uludağ Üniversitesi Tıp Fakültesi Klinik Araştırmalar Etik Kurulu tarafindan 2019-11/24 numaralı karar ile alındı. Çalışmaya 40 yaş altında olan, herhangi sistemik hastalığı olmayan, öncesinde pelvik enfeksiyon öyküsü olmayan, son 1 ay içerisinde antibiyotik kullanımı olmayan ve 5.günde taze - tek embriyo transferi uygulanan infertil hastalar dahil edildi. Tüm hastalardan onam alındı. Hastalar tüp bebek merkezi hemşiresi tarafından demografik özelliklerine bakılmaksızın randomize edilerek çalışma ve kontrol grubuna dahil edildi. Hastaların menstrual döngülerinin 3. gününde yapılan trans vajinal ultrasonografi ile antral folikül sayımları yapılıp, bazal hormonal değerlendirmeleri ile birlikte günlük gonadotropin dozları hesaplanarak kontrollü ovaryan hiperstimulasyona $(\mathrm{KOH})$ başlandı. KOH protokolü olarak sıklıkla antagonist ve daha az oranla mikrodoz agonist protokol seçilmiş olup stimulasyon sentetik folikül uyarıcı hormon (FSH) ya da insan menopozal gonadotropin (HMG) ile günlük enjeksiyonlar ile sağlandı. Hastalar aralıklı takipler ile trans vajinal ultrasonografi ile değerlendirilerek önde gelen folikül boyutu $14 \mathrm{~mm}$ olduğu zaman günlük antagonist (Certrorelix, 0,25 $\mathrm{mg}$ ) enjeksiyonlarına başlandı ve en az 3 folikül 17 $18 \mathrm{~mm}$ ve üzerinde çıktığında ise yumurta toplama (OPU) işlemi planlandı. OPU işleminin 34-36 saat öncesinde ovulasyonu sağlamak amacı ile $250 \mathrm{mcg}$ koriogonadotropin alfa enjeksiyonu yapıldı. Hastalara OPU işlemi genel anestezi altında steril ortamda, 17 gauge tek lümenli iğne ile trans vajinal ultrason eşliğinde yapıldı. Çalışma süresince OPU uygulanan ve taze embriyo transferi planlanan tüm hastalara OPU sonrasında daha önceden reçete edilmiş olan ve her tabletinde 100 milyon canlı laktobasil içeren 4 tablet (GYNOFLOR vajinal tablet, Abdi İbrahim İlaç, İstanbul Türkiye) vajina içerisine yerleştirildi. Kontrol grubunda yer alan hastalara herhangi bir ilaç uygulanmadı. Ve her hastaya OPU işleminde antibiyotik proflaksisi açısından 1x3 azitromisin $500 \mathrm{mg}$ tablet oral yoldan verildi. OPU sonrası toplanan oositler embriyoloji takibinde değerlendirildi. Maturasyonunu tamamlamış olan oositlere, hastanın eşinden alınan semen örneğinden izole edilmiş spermler ile intrasitoplazmik sperm enjeksiyonu (ICSI) işlemi uygulanarak fertilizasyon sağlandi. Oluşan embriyolar embriyoloji ekibi tarafından 2.gün, 3. Gün ve 5. Gün gözlenerek, pronukleus, klivaj ve blastokist aşamaları değerlendirildi ve var olan en iyi kalite blastokist transfer için hazırland1. Dorsolitotomide steril ortamda, trans abdominal ultrason eşliğinde hastalara embriyo transferi uyguland1. Transfer sonrası hastalar mobilize edildi. Luteal faz desteği olarak hastalara günlük iki dozda $90 \mathrm{mg}$ vajinal progesteron uyguland.

Embriyo transferi yapılmayan hastalar analize dahil edilmedi. Kontrol grubundaki hastalar için de tüp bebek prosedürleri çalışma grubundaki hastalar ile tamamen aynıydı. Çalışmanın birincil sonucu olarak, embriyo implantasyonu ele alındı. İmplantasyon intrauterin gestasyonel kesenin gözlenmesi şeklinde tanımlandi.

\section{Biyoistatistiksel Analiz}

Tüm değişkenlerin dağılımı histogramlar yapılarak görsel olarak değerlendirildi. Sürekli değişkenlerden normal dağılım gösterenler ortalama ve standart sapma ile normal dağ 1 lım göstermeyenler medyan ve 25 . - 75. çeyrek değerleriyle tanımlandı. Kategorik değişkenler oransal olarak tanımlandı. Gruplar arasındaki karşılaştırmalarda sürekli değişkenler için dağılım özelliklerine göre bağımsız örnekler için t - test (normal dağılım) veya Mann Whitney U test (normal dağ1lım olmayanlar) yapıldı. Kategorik değișkenler için kikare testi ve türevleri uygulandı. Çift yönlü $p$ değeri $<0.05$ olduğunda gruplar arasındaki farklar istatistiksel olarak anlamlı kabul edildi.

\section{Bulgular}

Çalışma grubunda 88, kontrol grubunda 88 olmak üzere toplam 176 hasta çalışmaya dahil edildi. Yaş ve vücut kitle indeksi (VKİ) her iki grupta benzerdi ( $\mathrm{S}_{1}-$ rasılya; Yaş $32.7 \pm 4.6$ ve $32.7 \pm 4.6$ p:0.98, VKİ 26.2 \pm 4.9 ve $24.1+4.7$ p:0.06). 3.gün serum FSH düzeyle- 


\section{Vajinal Laktobasil Kullanımının IVF Sonuçlarına Etkisi}

ri, 3.gün serum estradiol düzeyleri, anti-mülleryen hormon (AMH) düzeyleri ve antral folikül sayımları (AFS) her iki grupta benzer olarak sonuçlandı (Sırasiyla; FSH 4.5 (3.2-6.2) ve 5.3 (3.7-6.5) p:0.06, Estradiol 52(33-82) ve 47 (32-67) p:0.17, AMH 1.3 (0.76$2.4)$ ve 1.7 ((0.88-2.7) p:0.76, AFS 8 (6-13) ve 10 (613) p:0.78) Her iki grubun infertilite etiyolojisi benzerdi, iki grupta da yaklaşık 3 te 1 oranında düşük yumurtalık rezervi nedeniyle tüp bebek tedavisi uygulanmıştı. (Tablo-I) İki grupta da $\mathrm{KOH}$ protokolü olarak benzer şekilde çoğunlukla antagonist protokol (\%66 ve \%73 p:0.7) uygulanmıştı. Günlük gonadotropin ihtiyac1 her iki grupta da benzerdi (315 IU \pm 58 ve 307 IU \pm 68, p:0.44). Embriyoloji parametreleri; toplanan oosit say1s1, metafaz-2 (M2) oosit sayıs1, 2 Pronukleus (2PN) sayısı her iki grupta benzer olarak sonuçlandi. (Tablo-I) Çalışmanın birincil sonucu her iki grup arasındaki implantasyon oranları karşılaştırıldığında çalışma grubunda \%38,6 kontrol grubunda \%32,9 olmak üzere sonuçlar arasında çalışma grubunda oranlar daha yüksek olmasına rağmen anlamlı istatistiksel fark gözlenmedi (p:0.43). (Tablo-I)

Tablo I. Demografik Veri ve Gebelik Sonuçları

\begin{tabular}{|c|c|c|c|}
\hline & Çalışma Grubu & Kontrol Grubu & $p$ \\
\hline Yaş ${ }^{*}$ & $32.72 \pm 4.6$ & $32.7 \pm 4.6$ & 0.98 \\
\hline Vücut Kitle İndeksi & $26.2 \pm 4.9$ & $24.1 \pm 4.7$ & 0.06 \\
\hline FSH (IU/L) & $4.5(3.2-6.2)$ & $5.3(3.7-6.5)$ & 0.06 \\
\hline Estradiol (pg/ml) & $52(33-82)$ & $47(32-67)$ & 0.17 \\
\hline AMH (ng/ml) & $1.3(0.76-2.4)$ & $1.7((0.88-2.7)$ & 0.76 \\
\hline AFS & $8(6-13)$ & $10(6-13)$ & 0.78 \\
\hline \begin{tabular}{|l} 
Etiyoloji \\
Açıklanamayan \\
Anovulasyon \\
Düšük Over Rezer- \\
vi \\
Erkek Faktörü \\
Erkek \& Kadın \\
\end{tabular} & $\begin{array}{c}\% 19,3 \\
\% 4,5 \\
\% 34,1 \\
\% 21,6 \\
\% 20,5\end{array}$ & $\begin{array}{c}\% 23 \\
\% 4,4 \\
\% 36,8 \\
\% 21,8 \\
\% 14\end{array}$ & 0.78 \\
\hline $\begin{array}{l}\text { Stimulasyon } \\
\text { Protokolü }\end{array}$ & $\begin{array}{l}\text { \%66,3 Antagonist } \\
\% 33,7 \text { Mikrodoz }\end{array}$ & $\begin{array}{l}\text { \%73,2 Antagonist } \\
\% 26,8 \text { Mikrodoz }\end{array}$ & 0.71 \\
\hline $\begin{array}{l}\text { Günlük Gonadotro- } \\
\text { pin Dozu (Üni- } \\
\text { te/gün)* } \\
\end{array}$ & $315 \pm 58$ & $307 \pm 68$ & 0.44 \\
\hline $\begin{array}{l}\text { hCG günü Estradiol } \\
\text { (pg/ml) }\end{array}$ & $1338(813-2176)$ & 1599 (816-2085) & 0.67 \\
\hline Oosit & $8(5-11)$ & $8(5-13)$ & 0.7 \\
\hline M2 & $7(4-9)$ & $5(3-9)$ & 0.3 \\
\hline $2 \mathrm{PN}$ & $4(2-5)$ & $3(2-6)$ & 0.8 \\
\hline Implantasyon Oranı & $38.6 \%(34 / 88)$ & $32.9(29 / 88)$ & 0.43 \\
\hline
\end{tabular}

* işaretli parametreler standart sapmaları ile birlikte ortalama değerlerdir.

(FSH: Folikül Stimulan Hormon, AMH: Anti-Mulleryen Hormon, AFS: Antral folikül Sayısı, M2: metafaz2, 2PN: 2 pronukleus)

\section{Tartışma ve Sonuç}

Çalışmamızda sonuç olarak, tüp bebek tedavisi uygulanan infertil hastalarda luteal fazda vajinal laktobasil desteğinin, laktobasil kullanılmayan grupla karşılaştırıldığında implantasyon başarısına etki etmediği gözlendi.

Laktobasil kullanımındaki amaç bozulmuş olabilecek vajinal mikrobiyomun embriyo transferi öncesi normal florasını oluşturmaktı. Bozulmuş flora klinik pratikte karşımıza sıklıkla bakteriyel vajinozis olarak çıkmaktadır. Bakteriyel vajinozis (BV) üreme çağındaki kadınlarda en sık gözlenen vajinal enfeksiyon tablosudur ve vajinada var olan laktobasil hakimiyetinin kaybolması ve Gardnerella Vaginalis artmış kolonizasyonu ile oluşmaktadır. BV'in infertilite, erken doğum, endometrit ve pelvik enflamatuar hastalık gibi olumsuz sonuçlara yol açtığı yapılan çalışmalarda gösterilmiştir. ${ }^{10,11}$ Kyono ve arkadaşlarının çalışmasinda, ICSI tedavisi uygulanan hastaların embriyo kateterlerinde yapılan 16s rDNA gen analizi sonuçlarına göre, \%48.9 hastada laktobasil hakimiyeti kaybolmuş ve gebelik oranlarının sağlıklı gruba göre daha düşük olduğu raporlanmıştır. ${ }^{12}$ Ancak bu bozuk mikrobiyomun düzeltilmesi ve gebelik sonuçları ile ilişkisi oldukça sınırlı çalışmada irdelenmiştir. BV dışında, infertil hastalarda vajinal ve uterin mikrobiyomu bozan diğer bir faktör de $\mathrm{KOH}$ sırasında oluşan suprafizyolojik hormon seviyeleridir. ${ }^{13} \mathrm{KOH}$ sikluslarında suprafizyolojik gonadotropin düzeylerinin etkisi ve prematüre luteoliz nedeni ile endojen östrojen ve progesteron üretimi azalmaktadır. $\mathrm{Bu}$ sebeple başarılı implantasyon ve gebeliğin devamı için $\mathrm{KOH}$ siklusları progesteron desteği ile devam ettirilmelidir. Progesteron varlığının endometriyum üzerinde desidüzalizasyonun düzenlenmesi, reseptivitenin ve moleküler değişikliklerin ayarlanması gibi etkileri mevcuttur.

Ancak her ne kadar luteal fazda progesteron desteği sağlansa da $\mathrm{KOH}$ sikluslarında suprafizyolojik hormon seviyelerine bağlı olarak üreme sisteminde mikrobiyom etkilenmektedir. Bu sebeple belki de taze embriyo transferi yerine daha fizyolojik bir ortamda transfere olanak sağlayan donmuş embriyo transferi tercihi konusu tartışılmalıdır. Biz çalışmamızda taze embriyo transferlerinde luteal faz desteğinde laktobasil kullanımını araştırdık ancak donmuş embriyo transferlerinde laktobasil kullanımının implantasyona etkisini araştırmak mikrobiyotada suprafizyolojik hormonal etkiyi dışlamış olacaktır.

Vajinanın tersine uterin kavite yakın zamana kadar steril bir ortam olarak bilinmekteydi, ancak histerektomi spesmenlerinde yapilan incelemelerde endometriyumunda bir mikrobiyotaya sahip olduğu gösterildi. ${ }^{14}$ İmplantasyon üzerine mikrobiyom etkisini araşt1ran bir çalışmada infertil kadınların endometriyal sıvı örneklerinde incelemeler yapılmış ve laktobasil yo- 
ğunlukta (>\%90) ve laktobasil az yoğunlukta olan gruplar olarak ikiye ayrılmış ve laktobasil hakimiyetinin daha az olduğu grupta implantasyon, gebelik oranları ve devam eden gebelik oranlarında azalma olduğu gözlenmiştir. ${ }^{15}$ Biz de çalışmamızda bu sonuçtan yola çıkarak, luteal fazda laktobasil desteği ile implantasyon oranlarında olumlu sonuçlar almayı hedefledik. Ancak sonuçları değerlendirdiğimizde luteal fazda vajinal yolla laktobasil desteğinin implantasyon oranlarına etki etmediğini gözlemledik.

Literatürde OPU günü proflaktik antibiyotik kullanımının mikrobiyom üzerinde olumsuz etkileri olabileceğine dair yorumlar olsa da yapılan çalışmalarda kullanılan proflaktik antibiyotiğin laktobasil hakimiyetini azaltmadığ́ gözlemlenmiştir. Yapılan bir çalışmada doksisiklin bir başka çalışmada ise metronidazol için laktobasil seviyeleri irdelenmiş ve antibiyotik kullanımı sonrası embriyo kateterinde virulan bakteri miktarının azaldığı ve laktobasil hakimiyetinin değişmediği ve hatta gebelik oranlarını olumlu etkilediğ gözlenmiştir. ${ }^{16,17} \mathrm{Biz}$ de çalışmamızda OPU günü proflaktik olarak hem çalışma hem de kontrol grubunda azitromisin-1x3 tablet antibiyoterapi uyguladık.

Çalışmamız her ne kadar prospektif bir çalışma olsa da bazı sınırlılıkları mevcuttu. İlk olarak çalışma ve kontrol grubunda embriyo transfer günü vajinal mikrobiyomların değerlendirilmesi ve karşılaştırılması mevcut değildi. Bu değerlendirme sayesinde laktobasil kullanımının çalıșma grubunda etkilerini daha objektif olarak gözlemleyebilirdik. İkinci olarak literatürde vajinal florayı düzenlemesi amacıyla ne kadar dozda laktobasil kullanılacağına yönelik bir fikir birliği sağlanamamıştır. Biz çalışmamızda $1 \times 4$ tablet olarak vajinal laktobasil desteği uyguladık. Son olarak örneklem hacmi çalışmanın gücünü azaltmaktadır.

Sonuç olarak günümüzde artık endometriyal mikrobiyota varlığ kabul edilmiş olup, infertilitede, tekrarlayan implantasyon başarısızlıklarında vajinal ve endometriyal mikrobiyomun rolünün oldukça büyük olduğu bilinmektedir. Çalışmalar endometriyal mikrobiyotanın implantasyona en uygun şekliyle hazırlanması yönünde olmalıdır. Biz de çalışmamızda implantasyona olumlu katkı sağlayabilecek olan luteal laktobasil desteğini inceledik ancak, implantasyon oranları her ne kadar kontrol grubuna göre yüksek olsa da istatistiksel anlamlılığa ulaşamadı. Hipotezimiz örneklem hacmi daha büyük olan başka çalışmalar ile anlamlı sonuca ulaşabilir ve eş zamanlı endometriyal mikrobiyomun $16 \mathrm{~s}$ rDNA analizinin yapılması bu sonuçları daha da anlamlı kılabilir.

Etik Kurul Onay Bilgisi:

Onaylayan Kurul: Uludağ Üniversitesi Tıp Fakültesi Klinik Araştırmalar Etik Kurulu.

Onay Tarihi: 26.06.2019

Karar No: 2019-11/24

\section{Kaynaklar}

1. Lander ES, Linton LM, Birren B, Nusbaum C, Zody MC, Baldwin $\mathrm{J}$, et al. Initial sequencing and analysis of the human genome. Nature. 2001 Feb 15;409(6822):860-921.

2. Turnbaugh PJ, Ley RE, Hamady M, Fraser-liggett C, Knight R, Gordon JI. The human microbiome project: exploring the microbial part of ourselves in a changing world. Nature. 2007;449(7164):804-10.

3. Mendling W. Vaginal microbiota. In: Advances in Experimental Medicine and Biology. Springer New York LLC; 2016. p. 83-93.

4. Hurley E, Mullins D, Barrett MP, O’Shea CA, Kinirons M, Ryan CA, et al. The microbiota of the mother at birth and its influence on the emerging infant oral microbiota from birth to 1 year of age: a cohort study. J Oral Microbiol. 2019 Jan 1;11(1).

5. Kervinen K, Kalliala I, Glazer-Livson S, Virtanen S, Nieminen $\mathrm{P}$, Salonen A. Vaginal microbiota in pregnancy: Role in induction of labor and seeding the neonate',s microbiota? Vol. 44, Journal of biosciences. NLM (Medline); 2019.

6. Haahr T, Jensen JS, Thomsen L, Duus L, Rygaard K HP. Abnormal Vaginal Microbiota May Be Associated With Poor Reproductive Outcomes: A Prospective Study in IVF Patients PubMed. Hum Reprod. 2016;795-803.

7. Ravel J, Gajer P, Abdo Z, Schneider GM, Koenig SSK, McCulle SL, et al. Vaginal microbiome of reproductive-age women. Proc Natl Acad Sci U S A. 2011 Mar 15;108(SUPPL. 1):4680-7.

8. Tachedjian G, Aldunate M, Bradshaw CS, Cone RA. The role of lactic acid production by probiotic Lactobacillus species in vaginal health. Res Microbiol. 2017 Nov 1;168(9-10):782-92.

9. R Koedooder, M Singer, S Schoenmakers , P H M Savelkoul, S A Morré, J D de Jonge, L Poort, W J S S Cuypers, N G M Beckers, F J M Broekmans, B J Cohlen, J E den Hartog, K Fleischer, C B Lambalk, J M J S Smeenk, A E Budding JSEL. The Vaginal Microbiome as a Predictor for Outcome of in Vitro Fertilization With or Without Intracytoplasmic Sperm Injection: A Prospective Study - PubMed. Hum Reprod. 2019. p. 1042-54.

10. Mangot-Bertrand J, Fenollar F, Bretelle F, Gamerre M, Raoult D, Courbiere B. Molecular diagnosis of bacterial vaginosis: Impact on IVF outcome. Eur J Clin Microbiol Infect Dis. 2013 Apr;32(4):535-41.

11. Brabant $\mathrm{G}$. Bacterial vaginosis and spontaneous preterm birth. J Gynecol Obstet Biol la Reprod. 2016 Dec 1;45(10):1247-60.

12. Kyono K, Hashimoto T, Kikuchi S, Nagai Y, Sakuraba Y. A pilot study and case reports on endometrial microbiota and pregnancy outcome: An analysis using 16S rRNA gene sequencing among IVF patients, and trial therapeutic intervention for dysbiotic endometrium. Reprod Med Biol. 2019 Jan 1;18(1):72-82.

13. Hyman RW, Herndon CN, Jiang H, Palm C, Fukushima M, Bernstein D, et al. The dynamics of the vaginal microbiome during infertility therapy with in vitro fertilization-embryo transfer. J Assist Reprod Genet. 2012 Feb;29(2):105-15.

14. Miles SM, Hardy BL, Merrell DS. Investigation of the microbiota of the reproductive tract in women undergoing a total hysterectomy and bilateral salpingo-oopherectomy. Fertil Steril. 2017 Mar 1;107(3):813-820.e1.

15. Moreno I, Codoñer FM, Vilella F, Valbuena D, MartinezBlanch JF, Jimenez-Almazán J, et al. Evidence that the endometrial microbiota has an effect on implantation success or failure. In: American Journal of Obstetrics and Gynecology. Mosby Inc.; 2016. p. 684-703.

16. Moore DE, Soules MR, Klein NA, Fujimoto VY, Agnew KJ, Eschenbach DA. Bacteria in the transfer catheter tip influence the live-birth rate after in vitro fertilization. Fertil Steril. 2000;74(6):1118-24.

17. Selim SA, El Alfy SM, Aziz MHA, Mohamed HM, Alasbahi AA. Effective of metronidazole to bacterial flora in vagina and the impact of microbes on live birth rate during intracytoplasmic sperm injection (ICSI). Arch Gynecol Obstet. 2011 Dec;284(6):1449-53. 